\title{
SISTEM KOMUNIKASI JARAK JAUH ALAT PENGUKUR KECEPATAN DAN ARAH ANGIN
}

\author{
Jamalludin \\ Jurusan Teknik Elektronika dan Informatika \\ Politeknik Manufaktur Negeri Bangka Belitung \\ Jl. Timah Raya Kawasan Industri Airkantung Sungailiat-Bangka 33211, Tel: 0717-93586, Fax. 0717-93585 \\ idoe jam88@yahoo.com
}

\begin{abstract}
The process of measuring wind speed and its direction is still manual and considered inefficient. The purpose of making these tools is to help get the data of speed and direction of the wind from a distance in order to work more eficient. In determining the wind speed is done by chopping round of the wind speed sensor by using an encoder while the determination of the wind direction is done by reading the orientation of magnetic hall sensor, constructed as wind direction. Utilizing the Arduino Mega 2560 Microcontroller as controller, the data is recorded with a cycle which can be set. The data that has been recorded is sent to Sim900a GSM shield in the form of SMS. Then the data is received by GSM shield the server and sent to the computer. The results of this system is able to measure and store data speed and direction of the wind from a distance. With a wind speed error of $4.56 \%$ of the measurements manually, and wind direction indicates the actual wind direction.
\end{abstract}

Keywords: Wind, Arduino Mega 2560, GSM Shield, Microcontroller, Sensor

\begin{abstract}
Abstrak
Proses pengukuran data kecepatan dan arah angin yang masih manual dinilai tidak efisien. Tujuan pembuatan alat ini untuk membantu mendapatkan data kecepatan dan arah angin dari jarak jauh agar pekerjaan lebih efisiesi. Dalam penentuan kecepatan angin dilakukan dengan cara mencacah putaran kecepatan angin menggunakan sensor encoder sedangkan penentuan arah angin dilakukan dengan cara membaca arah posisi hall magnetik sensor yang disusun seperti penunjuk arah angin. Memanfaatkan Mikrokontroler Arduino mega 2560 sebagai kontroller, data data tersebut direkam dengan siklus yang dapat diatur. Data yang telah direkam dikirim GSM shield Sim900a dalam bentuk SMS. Kemudian data diterima oleh GSM shield server dan dikirim ke komputer. Hasil dari sistem ini adalah dapat mengukur dan menyimpan data kecepatan dan arah angin dari jarak jauh. Dengan error kecepatan angin sebesar $4.56 \%$ dari pengukuran secara manual, dan arah angin menunjukan arah angin yang sebenarnya.
\end{abstract}

Kata kunci: Angin, Arduino Mega 2560, GSM Shield, Mikrokontroler, Sensor

\section{PENDAhULUAN}

Informasi tentang data kecepatan angin dan arah angin sangatlah diperlukan oleh masyarakat terutama yang profesinya sebagai nelayan, umumnya informasi tersebut dapat didapatkan pada dinas terkait. Proses untuk mendapatkan data kecepatan angin dan arah angin masih dilakukan secara manual, yakni petugas melakukan pengukuran secara langsung pada titik-titik tertentu. Tentunya proses seperti ini tidaklah efisien dan data yang diperoleh pun kurang real dikarenakan data yang didapatkan hanya 1 kali dalam sehari. Mengingat kondisi cuaca yang dapat berubah-ubah maka tentu akan berdampak berbahaya bagi para nelayan. Sehingga sangatlah diperlukan inovasi yang mampu memecahkan permasalahan tersebut. Dengan inovasi sistem yang mampu mengirimkan data kecepatan angin dan arah angin pada waktu real maka masyarakat bisa mendapatkan data kecepatan angin dan arah angin secara maksimal. Dalam proses pembuatan alat ini sangatlah diperlukan pembelajaran 
tentang alat ukur kecepatan angin dan arah angin, mikrokontroler, transfer data berbasis SMS dan pengolahan data pada komputer.

\section{METODE PENELITIAN}

Penjelasan tahapan penelitian dapat dijelaskan sebagai berikut:

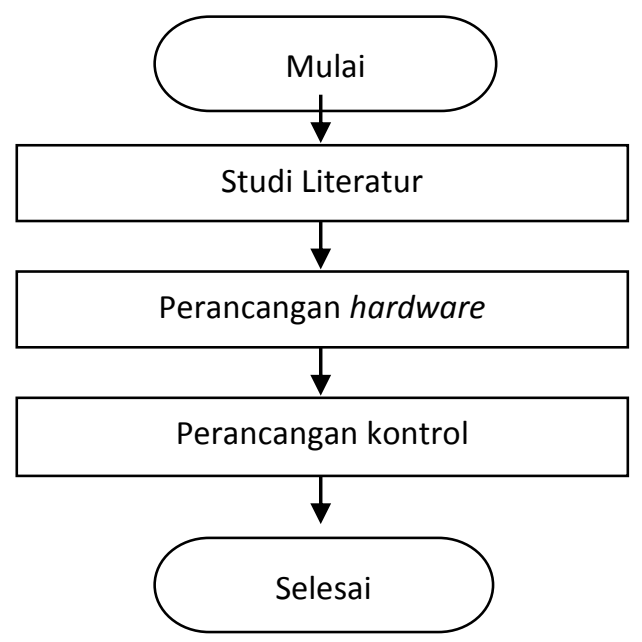

Gambar 1. Flowchart Tahapan Penelitian

\subsection{Studi Literatur}

Pengumpulan data ini berfungsi untuk mengetahui kebutuhan-kebutuhan teknologi tentang suatu jenis alat atau mencari kemungkinan-kemungkinan yang akan dibuat.

\subsection{Perancangan Hardware}

Perancangan hardware bertujuan untuk membuat suatu rancangan yang dapat dibuat dengan waktu yang efisien, adapun rancangan hardware terdiri dari konstruksi yang sesuai, letak komponen, dan fungsi komponen. Hardware yang dirancang diharapkan dapat berfungsi dengan baik.

\subsection{Perancangan Sistem Kontrol}

Perancangan sistem kontrol bertujuan untuk membuat suatu rancangan kontrol yang dapat mengontol system hardware dengan baik agar sistem dapat berjalan sesuai yang diinginkan.

\section{HASIL DAN PEMBAHASAN}

Pengukuran keceptan angin menggunakan sensor pembaca kecepatan yaitu optocoupler yang menghasikan sinyal pulsa yang kemudian sinyal tersebut diolah menjadi satuan kecepatan angin. Arah angin menggunakan sensor hall magnetic, sensor ini akan bekerja ketika didekatkan dengan magnet. Pada sensor arah angin ini mengunakan 8 buah sensor hall magnetic yang disusun mengikuti 8 arah mata angin. Magnet dipasangan dengan shaft dudukan sirip angin yang membentuk huruf L. Waktu pengiriman dapat diatur sesuai operator dan terdapat waktu default-nya 1 menit ketika waktu belum diatur. Data yang dikirim dalam bentuk SMS, jumlah data pengukuran angin yang dikirim sebanyak 10 data, data tersebut terdiri dari kecepatan angin, arah angin, dan waktu pengambilan data. Jika waktu pengiriman sudah terpenuhi maka data tersebut akan dikirim menggunakan GSM shiled. Data akan diterima oleh GSM shield dengan nomor operator yang telah ditentukan. Data akan diterima oleh GSM shield dengan nomor tujuan yang telah ditentukan, kemudian data diproses oleh Arduino yang terhubung dengan komputer setelah itu data ditampilkan dalam bentuk tabel dan grafik pada aplikasi interface. Power supply yang digunakan berasal dari baterai yang menghasilkan output sebesar 5V $1 \mathrm{~A}$. Berikut blok diagram alat yang dibuat : 


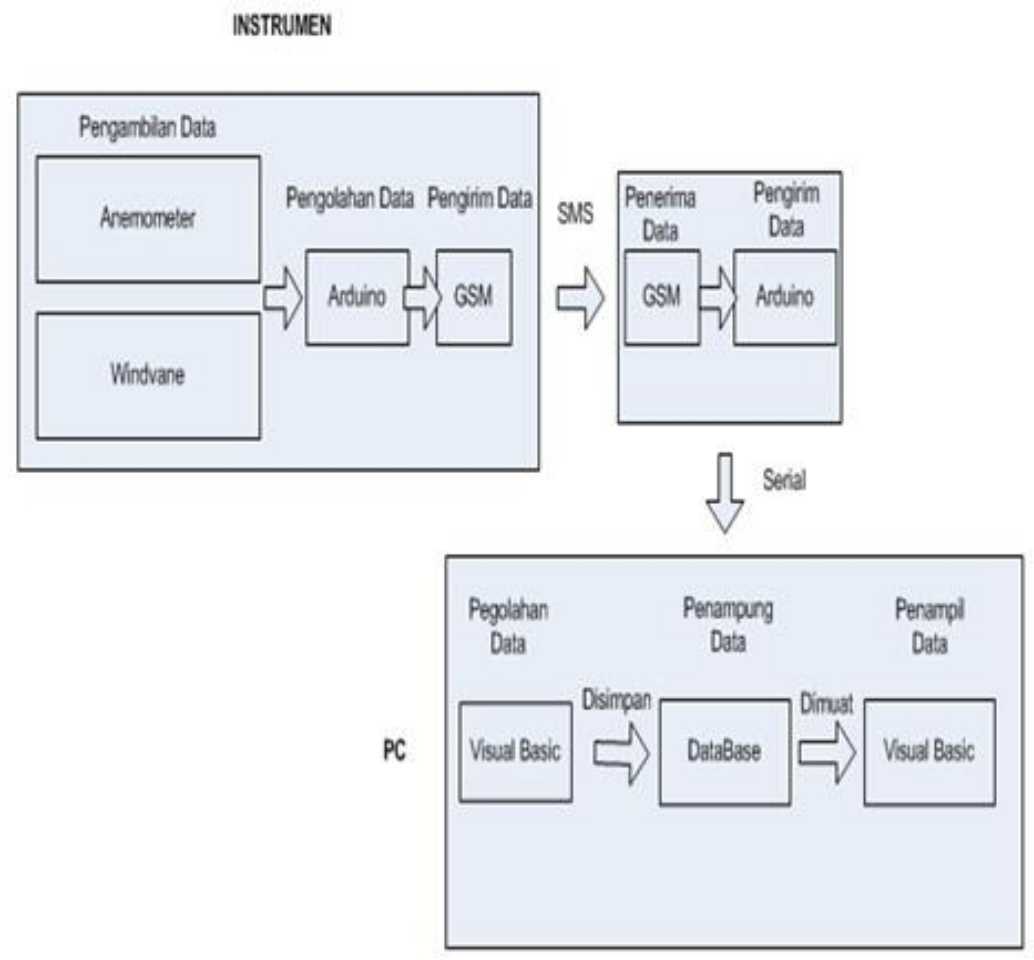

Gambar 2. Blok Diagram Alat

\subsection{Alat Ukur Kecepatan Angin dan Arah Angin (Instrumen)}

Bagian ini merupakan alat yang diaplikasikan untuk mendapatkan kecepatan angin dan arah angin sekaligus langsung mengirimkan data ke user dengan rentan waktu yang dapat ditentukan dengan memanfaatkan komunikasi SMS aplikasi GSM shield. Kerangka alat ini menggunakan pipa paralon agar mudah dalam pemasangan dan memindahkan alat, pipa yang digunakan terdiri dari beberapa ukuran yang dipasang dan disusun seperti gambar berikut:
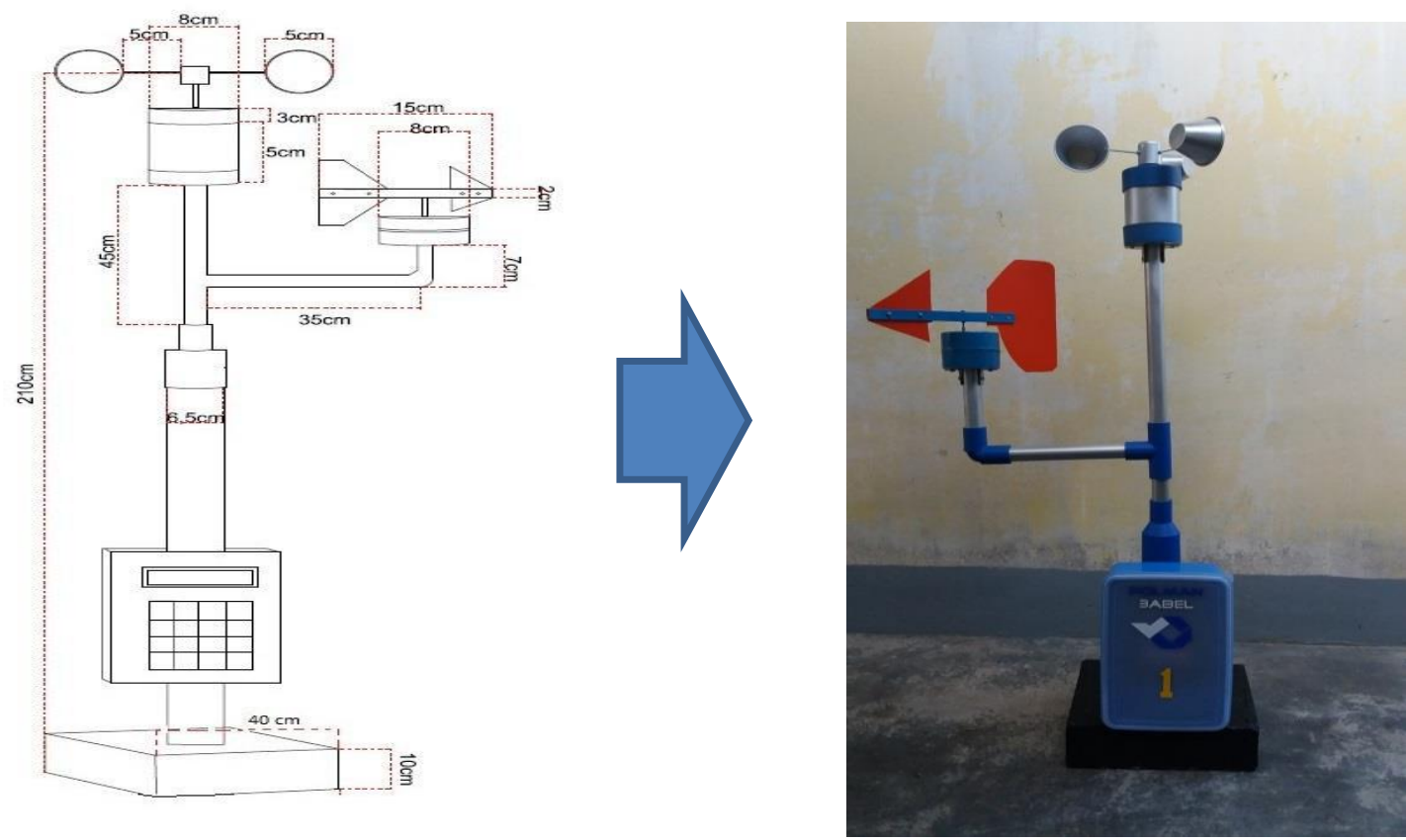

Gambar 3. Kerangka Alat 


\subsection{Rangkaian Kontrol}

kontrol yaitu

Dalam perancangan hardware pada penelitian ini penulis mengaplikasikan beberapa rangkaian

a. Arduino UNO,

b. GSM Shield,

c. RTC.

d. Sensor Kecepatan Angin (Rotary encoder)

e. Sensor Arah Angin (Half magnetic)

Gambar skematik rangkaian control secara keseluruhan ditunjukan pada gambar dibawah ini:

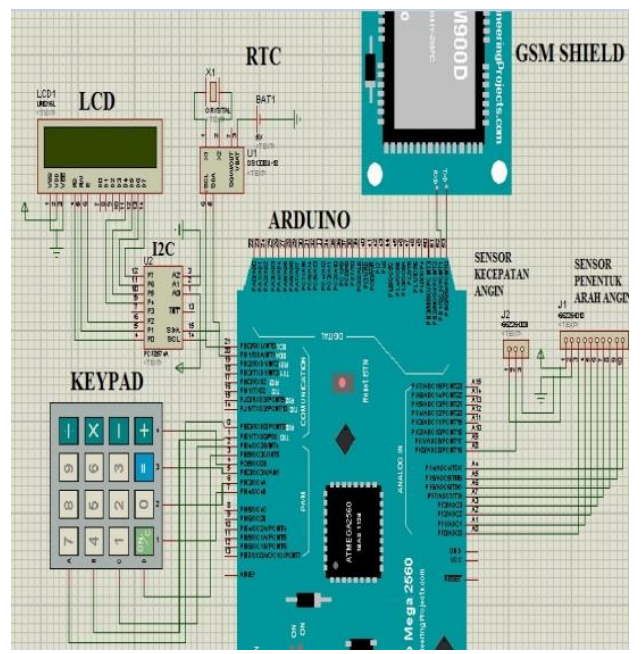

Gambar 4. Skematik Rangkaian Kontrol

Setelah persiapan keseluruhan rangkaian kontrol sudah siap tahapan selanjutnya perakitan dan instalasi alat. Pada tahap perakitan dilakukan pemasangan sensor kecepatan dan arah angin pada kerangka alat, selanjutnya proses instalasi yaitu melakukan pemasangan kabel-kabel dari sensor-sensor, LCD, RTC, Keypad dan GSM Shield pada box panel. Susunan rangkaian kesuluruhan alat yang sudah dipasang ditunjukan pada gambar dibawah ini.
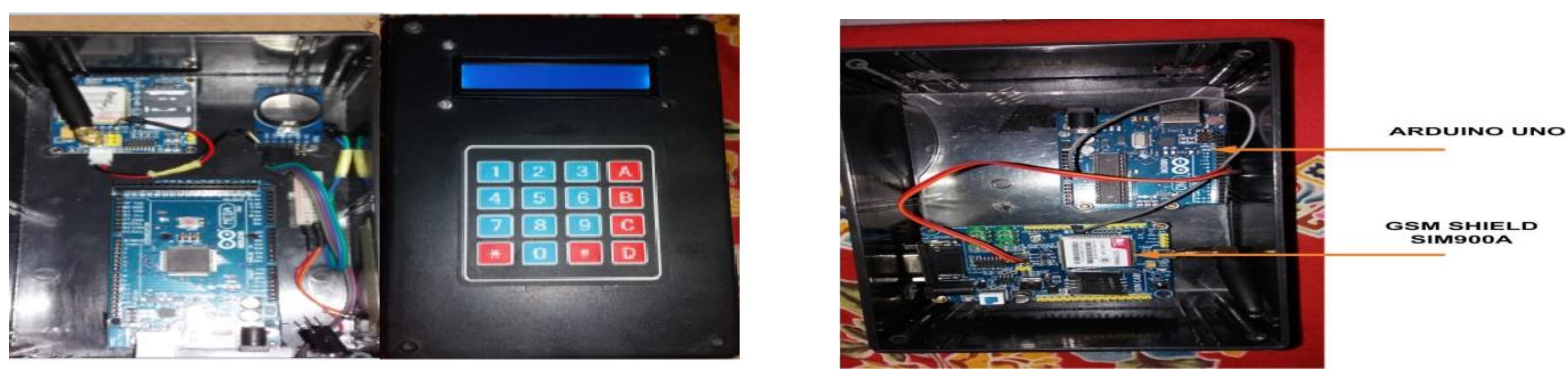

\subsection{Pengujian}

Gambar 5. Susunan Rangkaian

Cara kerja dari alat ini yaitu alat ukur yang diletakan pada masing-masing titik pengukuran pada area yang telah ditentukan dangan ketentuan daerah tersebut harus terjangkau oleh jaringan operator. Dalam kondisi default atau waktu sebelum diatur, maka data dikirim dalam waktu 1 menit sekali. Waktu pengiriman diatur 1 jam maka pada LCD akan muncul waktu pengaturan 60 menit, pengaturan waktu pada alat dimulai dari 1 menit. Kemudian selama dalam waktu 1 jam data pengukuran disimpan, jumlah data yang disimpan yaitu sebesar 10 data, terdiri dari kecepatan angin, arah angin dan waktu pengukuran. Jadi jika waktu pengiriman diatur 1 jam maka terdapat 10 data pengukuran dengan waktu perekaman 1 data per 6 menit. Kemudian jika waktu pengiriman terpenuhi maka data akan dikirim 
sesuai dengan nomor tujuan yang telah diprogram, pengiriman data melalui media sms. Data akan diterima oleh penerima (reciever) yang sebelumnya yang sudah diatur dalam posisi untuk menerima data dan juga telah dihubungkan dengan program visual basic pada laptop. Data yang masuk diproses oleh program visual basic lalu data disimpan pada database dan ditampilkan dalam bentuk tabel dan grafik seperti pada gambar dibawah ini:

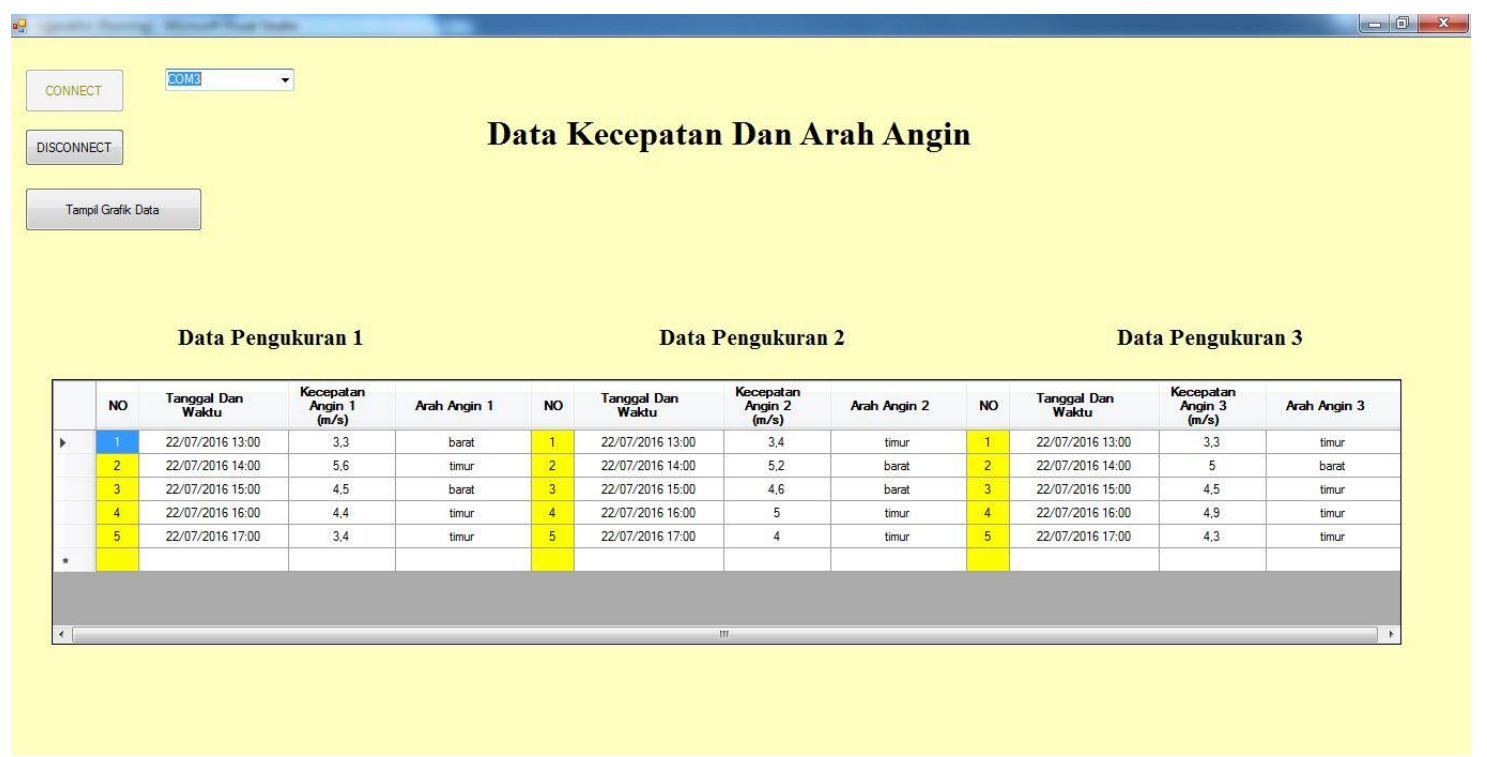

Gambar 6. Data Kecepatan dan Arah Angin

Setelah melakukan pengujian alat selanjutnya pengambilan data pengukuran. Berikut ini datadata hasil pengukuran yang didapat ditunjukan pada tabel dibawah ini

Tabel 1. Pengukuran Titik 1

\begin{tabular}{llll}
\hline No & Waktu & Kecepatan Angin $(\mathrm{Km} / \mathrm{j})$ & Arah Angin \\
\hline 1 & $8 / 8 / 2016$ 1:51PM & 13.86 & Barat \\
2 & $8 / 8 / 2016$ 1:53PM & 14.04 & Barat \\
3 & $8 / 8 / 2016$ 1:55PM & 18.07 & Barat Daya \\
4 & $8 / 8 / 2016$ 1:57PM & 17.54 & Barat \\
5 & $8 / 8 / 20161: 59 \mathrm{PM}$ & 12.98 & Barat \\
6 & $8 / 8 / 2016$ 2:01PM & 9.12 & Barat \\
7 & $8 / 8 / 2016$ 2:03PM & 5.26 & Barat \\
8 & $8 / 8 / 2016$ 2:05PM & 4.91 & Barat \\
9 & $8 / 8 / 2016$ 2:07PM & 5.61 & Barat \\
10 & $8 / 8 / 20162: 09 P M$ & 6.84 & Barat \\
\hline & & Tabel 2. Pengukuran Titik 2 & \\
\hline No & Waktu & Kecepatan Angin $(\mathrm{Km} / \mathrm{j})$ & Arah Angin \\
\hline 1 & $8 / 8 / 20161: 45 \mathrm{PM}$ & 10.18 & Barat \\
2 & $8 / 8 / 20161: 47 \mathrm{PM}$ & 10.35 & Barat \\
3 & $8 / 8 / 20161: 49 \mathrm{PM}$ & 12.28 & Barat Daya \\
4 & $8 / 8 / 20161: 51 \mathrm{PM}$ & 12.18 & Barat \\
5 & $8 / 8 / 20161: 53 \mathrm{PM}$ & 12.66 & Barat \\
6 & $8 / 8 / 20161: 55 \mathrm{PM}$ & 14.85 & Barat \\
7 & $8 / 8 / 20161: 57 \mathrm{PM}$ & 20.9 & Barat \\
8 & $8 / 8 / 20161: 59 \mathrm{PM}$ & 4.9 & Barat Laut \\
9 & $8 / 8 / 20162: 01 \mathrm{PM}$ & 9.98 & Barat Laut \\
10 & $8 / 8 / 20162: 03 \mathrm{PM}$ & 12.7 & Barat Laut \\
\hline & & &
\end{tabular}


Tabel 3. Pengukuran Titik 3

\begin{tabular}{llll}
\hline No & Waktu & Kecepatan Angin $(\mathrm{Km} / \mathrm{j})$ & Arah Angin \\
\hline 1 & $8 / 8 / 2016$ 1:52PM & 21.4 & Barat Daya \\
2 & $8 / 8 / 2016$ 1:54PM & 19.3 & Barat \\
3 & $8 / 8 / 20161: 56 \mathrm{PM}$ & 20.35 & Barat \\
4 & $8 / 8 / 20161: 58 \mathrm{PM}$ & 19.3 & Barat \\
5 & $8 / 8 / 20162: 00 \mathrm{PM}$ & 17.19 & Barat \\
6 & $8 / 8 / 20162: 02 \mathrm{PM}$ & 19.47 & Barat \\
7 & $8 / 8 / 20162: 04 \mathrm{PM}$ & 18.07 & Barat \\
8 & $8 / 8 / 20162: 06 \mathrm{PM}$ & 12.98 & Barat Laut \\
9 & $8 / 8 / 20162: 08 \mathrm{PM}$ & 14.91 & Barat Laut \\
10 & $8 / 8 / 20162: 10 \mathrm{PM}$ & 7.19 & Barat Laut \\
\hline
\end{tabular}

\section{SIMPULAN}

Setelah melakukan tahap perancangan dan pembuatan sistem yang kemudian dilanjutkan dengan tahap pengujian maka dapat diambil kesimpulan sebagai berikut:

1. Desain sistem pengukuran jarak jauh dengan transmisi data menggunakan GSM pengukuran jarak jauh dapat dilakukan pada tiga tempat pengukuran secara bersamaan, desain hardware alat dapat dibongkar pasang dengan ketinggian alat setelah dipasang adalah $2 \mathrm{~m}$.

2. Sistem transmisi data menggunakan SMS melalui jaringan GSM hanya dapat dilakukan pada daerah yang memiliki jaringan GSM.

3. Berdasarkan hasil pengukuran kecepatan secara jarak jauh dan pengukuran manual didapatkan error sebesar $4.56 \%$ dan untuk arah angin telah menunjukan arah angin yang sebenarnya.

\section{DAFTAR PUSTAKA}

[1]. Andrianto Heri, Darmawan Aan, "Arduino Belajar Cepat Dan Pemrograman", Bandung : Informatika Bandung, 2016.

[2]. Dewi Wijayanti, Endah Rahmawati dan Imam Sucahyo"Rancang Bangun Alat Ukur Kecepatan Dan Arah Angin Berbasis Arduino Uno Atmega 328p “, diakses pada 17 juni 2016, <ejournal.unesa.ac.id/article>.

[3]. Banodin, Rizal and Fatchur Rochim , Adian and Andromeda, Trias, "ALAT PENUNJUK ARAH ANGIN DAN PENGUKUR KECEPATAN ANGIN BERBASIS MIKROKONTROLLER AT89C51.", diakses pada 10 juni 2016, <http://eprints.undip.ac.id/25737/> 